\title{
O USO DAS TECNOLOGIAS DIGITAIS DA INFORMAÇÃO E COMUNICAÇÃO NAS PRÁTICAS PEDAGÓGICAS DOS PROFESSORES DA EDUCAÇÃO BÁSICA
}

\author{
Mariangela Kraemer Lenz Ziede ${ }^{1}$ \\ Ezequiel Theodoro da Silva ${ }^{2}$ \\ Ludimar Pegoraro ${ }^{3}$
}

\section{INTRODUÇÃO}

Este estudo ${ }^{4}$ tem como objetivo principal a análise de como os professores da educação básica do município de Caçador/SC vêm utilizando as TDIC nas suas práticas pedagógicas. Como objetivos específicos, desejamos compreender a vinculação teoria-prática que orienta o fazer docente, transformando seus conhecimentos em prática pedagógica, escolhendo e organizando conteúdos que tomem a interdisciplinaridade como princípio; verificar o significado do papel do professor no que diz respeito a sua função como problematizador e orientador dos processos individuais e coletivos de aprendizagem na educação básica ao invés de simples transmissor de conhecimento.

Segundo (ALMEIDA E VALENTE, 2011),

é preciso privilegiar processos de formação que permitam o movimento teoria à prática e vice-versa, levando o docente a perder o medo e a olhar para suas próprias práticas, desconstruí-las e construí-las a favor dos alunos, pois é preciso compreender a necessidade de ir além do currículo do lápis e do papel, utilizado para representar e explicitar os conhecimentos dos alunos.

Não resta dúvida de que as múltiplas discussões sobre a relação entre educação e uso das tecnologias produzem um efeito deveras positivo para a conquista de uma escola de melhor qualidade. De fato, considerando o contexto geral das

\footnotetext{
1 Doutora em Educação (UFRGS/RS). Professora-pesquisadora dos Mestrados Profissional em Educação Básica e Acadêmico em Desenvolvimento e Sociedade da UNIARP-Caçador, SC. E-mail: mariangelaziede@gmail.com

2 Doutor em Educação (PUC/SP). Coordenador do Mestrado Profissional em Educação Básica da UNIARP-Caçador, SC. E-mail - emarthi@outlook.com.br

3 Doutor pela UFRGS e Professor-pesquisador na UNIARP/SC. Coordenador e Professor do mestrado Acadêmico em Desenvolvimento e Sociedade e Professor do Mestrado Profissional em Educação básica.

${ }^{4} \mathrm{O}$ estudo contou com a participação das graduandas Andreza de Oliveira M. da Silva (Bolsista FAP) e Aline Fernanda W. de Carvalho (Bolsista Art. 170).
} 
transformações sociais, nestas últimas três décadas a tecnologia foi fortemente integrada nas nossas vidas e o impacto maior ocorreu na esfera do acesso a informação disponível na web. Tal mudança diretamente afetou as maneiras de se "fazer educação", sendo mais do que comum, hoje em dia, acompanhar na mídia (falada, televisiva, impressa e/ou virtual) entrevistas, reflexões e depoimentos de educadores a respeito da inserção, cada vez mais crescente, de notebooks, tablet, celulares e outros recursos tecnológicos em sala de aula.

No documento "Elementos conceituais e metodológicos para definição dos direitos de aprendizagem e desenvolvimento do ciclo de alfabetização do ensino fundamental" (BRASIL,2012) podemos observar que a utilização das TDIC na educação básica está prevista em muitos de seus objetivos. E também traz um outro conceito de escrita para a escola, a escrita hipertextual, utilizando a tela, o teclado e o mouse ao invés de lápis e papel, possibilitando modificações no próprio processo mental do estudante. Tais mudanças estão previstas pelo MEC, mas será que os professores realmente estão utilizando a tela e o teclado? Todas as escolas têm computadores funcionando? A formação de professores, contempla o uso das TDIC?

\section{UM RECORTE SOBRE EDUCAÇÃO E TDIC}

Nas últimas décadas houve muitas discussões a respeito da educação, os currículos adaptados as demandas da sociedade e novos paradigmas de aprendizagem lançados, porém silenciosamente os nativos digitais adotaram a tecnologia e desenvolveram estratégias de aprendizagem e de relacionamento com seus pares.

Justificativas ainda mais robustas para este trabalho podem ser encontradas na seguinte colocação de Belloni (1995, p. 12):

A educação das mídias é condição necessária na educação para cidadania, sendo um instrumento fundamental para a democratização das oportunidades educacionais e do acesso ao saber e, portanto, de redução das desigualdades sociais.

É possível observar que nesta citação o autor lança um alerta para o fato de que o acesso às mídias e a aprendizagem do seu manejo situam-se no contexto maior dos desafios da política educacional brasileira, por estarem relacionadas à problemática 
da igualdade social pelo viés da democratização de oportunidades de acesso à escola e ao conhecimento. E esse lugar destaque fica ainda mais evidente à luz de um fenômeno constatado por Demo (2011, p.16) quando afirma que "persiste ainda vazio significativo entre o potencial das novas tecnologias e a prática escolar. Esta tende a continuar a mesma, e, quando lança mão de novas tecnologias, as usa para adornar vezos tradicionais".

Essa afirmação destaca exatamente o fato de que a educação através do uso das mídias é uma condição necessária, mas não suficiente para superar os problemas existentes na área educacional - problemas esses que estão muito além da presença e do uso de mídias pelos professores. Nestes termos, as tecnologias não podem e não devem ser tomadas como uma panaceia à multiplicidade de necessidades, de desníveis e de diferenças enraizadas na nossa estrutura social. Por outro lado, conforme o alerta feito por Demo (2011), as novas tecnologias não devem ser tomadas como meras maquiagens ou adornos às práticas de ensino, devendo ser introduzidas e utilizadas nas escolas no intuito de superar as posturas tradicionais e esclerosantes dos professores.

Uma das soluções para esse impasse está na possibilidade de educadores também participarem das equipes produtoras dessas novas tecnologias educativas. Para isso é preciso que os cursos de formação de professores se preocupem em lhes garantir essas novas competências. Que ao lado do saber científico e do saber pedagógico, sejam oferecidas ao professor as condições para ser agente, produtor, operador e crítico dessas novas educações mediadas pelas tecnologias eletrônicas de comunicação e informação (KENSKI, 2003, p. 49-50).

Os professores precisam experenciar e tomar consciência da importância da tecnologia nos processos de ensino e de aprendizagem.

Uma preocupação sadia com os destinos e a qualidade da educação precisa ser estendida à compreensão e ao manejo da mídia indistintamente, sob o risco de, com a supressão ou o apagamento de um ou outro recurso ou tecnologia no âmbito do trabalho pedagógico, levarmos adiante uma educação fora do seu tempo, além, é claro, de não aproveitarmos as características dos diferentes veículos e linguagens para a melhoria dos processos de ensino-aprendizagem. Quer dizer, a escola e os professores devem selecionar criticamente os meios ou os veículos comunicacionais conforme a natureza do objeto ou conteúdo a ser ensinado, sabendo justificar os porquês dessa seleção (SILVA, 2005, p.33). 
A maioria dos professores teve a sua formação com pouca ou nenhuma das tecnologias que hoje temos a nossa disposição. O professor precisa estar em constante evolução devido às mudanças da sociedade e para tal precisar integrar os seus conhecimentos construídos ao longo do tempo às tecnologias disponíveis.

\section{PERCURSO METODOLÓGICO}

Para a coleta de dados elaboramos um questionário online no Google docs, contendo 33 questões divididas em objetivas e abertas, para que os professores pudessem descrever as suas experiências. Enviamos para o e-mail dos professores e realizamos também entrevistas com alguns professores que optaram por responder 0 documento impresso. O projeto foi submetido e aprovado pelo comitê de ética e está registrado na Plataforma Brasil sob o número 45329515400005593.

O estudo foi desenvolvido dentro de uma perspectiva de análise qualitativa considerando-se cinco categorias construídas a partir do referencial teórico. i) formação de professores para o uso das TDIC na educação básica; ii) a utilização da tecnologia como parte integrante no Projeto Político Pedagógico da escola; iii) desenvolvimento de projetos pelos professores usando as TDIC; iv) a contribuição das tecnologias para o processo de ensino e de aprendizagem; v) a utilização das TDIC no processo de avaliação.

\section{ANÁLISE DOS DADOS}

O questionário foi respondido por 37 professores das redes municipal e estadual de ensino de Caçador/SC, sendo $81 \%$ dos participantes da pesquisa mulheres, com idades variando entre 20 e 54 anos. Quanto ao nível de formação, 39\% eram graduados; $58 \%$ Especialistas; e 3\% com mestrado. Seus nomes foram substituídos por P1, P2, P3... P37, para manter o anonimato.

A análise dos dados pretendeu explicitar como os professores da educação básica do município de Caçador/SC vêm utilizando as TDIC nas suas práticas 
pedagógicas e, consequentemente, para incrementar os processos de ensino e de aprendizagem.

E para tal elencamos cinco categorias, descritas no decorrer da análise dos dados.

\section{Categoria 1: A formação de professores para o uso das TDIC na educação básica}

Nesta categoria analisamos a formação dos professores, as dificuldades e as superações no uso da tecnologia nas escolas.

Os professores relatam que a maior dificuldade é o fato de as escolas disponibilizarem equipamentos antigos, com poucos recursos e sem conexão. E também muitas vezes as formações são teóricas, dificultando a apropriação por parte dos professores.

P5. Na medida do possível busco formações, pois procuro constante atualização dos conteúdos. Quanto aos alunos ainda é pouco, pois nem todos têm acesso em casa a essa tecnologia. ${ }^{5}$

Alguns entrevistados citam que na sua formação inicial não utilizavam a tecnologia e por isso têm dificuldades de utiliza-las como parte integrante das atividades em sala de aula.

P19. Não totalmente. Somos resultado de uma prática pedagógica, na qual não existiam muitas tecnologias e quando utilizadas em sala de aula eram com o objetivo de recreação e não necessariamente como instrumento dos processos de ensino e aprendizagem.

Belloni (2001) afirma que é tudo muito novo, demanda novas concepções metodológicas muito diferentes das metodologias tradicionais, nas quais o professor é o centralizador da aprendizagem, baseado num discurso científico linear. Nesse sentido, o papel do professor é fundamental para o sucesso do uso das TDIC na educação.

\footnotetext{
${ }^{5}$ Para diferenciar as citações destacadas das entrevistas utilizamos, no corpo do texto, na mesma fonte, tamanho maior que as citações e menor que o normal, em espaço simples.
} 
Segundo Ziede e Aragón (2014), o professor precisa dar condições para que esse aluno possa buscar conhecimento, desafiando e criando situações que o desequilibrem e o motivem, mas muitas vezes o professor se sente desmotivado pela falta de incentivo na escola.

\title{
Categoria 2. A utilização da tecnologia como parte integrante no Projeto Político Pedagógico da escola.
}

Nesta categoria analisamos se/como o uso das tecnologias é contemplado no PPP das escolas e se os professores têm acesso a este documento.

Muitos professores participantes da pesquisa responderam que "desconhecem", ou "que o PPP está em fase de construção". Ou que a tecnologia aparece "basicamente como um projeto auxiliar". Poucos relataram que tem acesso ao PPP e que a tecnologia está contemplada.

Para exemplificar analisamos "o item tecnologia" no PPP de duas escolas, e para manter $\mathrm{o}$ anonimato, chamamos de escola $\mathrm{X}$ e escola $\mathrm{Y}$.

$\mathrm{Na}$ escola $\mathrm{X}$, a tecnologia está contemplada no planejamento do "Projeto Informática" que consta no documento da escola.

\begin{abstract}
A tecnologia vem para provocar mudanças pedagógicas, onde professores e alunos têm a oportunidade de interação imediata [...]. Para tanto as tecnologias devem ser encaradas como um projeto que seja feito coletivamente e partilhado entre os diversos profissionais da unidade escolar. O poder e a influência só poderão ser revertidos em conhecimento escolar na medida em que forem aplicadas em conjunto e com reflexões compartilhadas (PPP, escola X).
\end{abstract}

Podemos observar que a tecnologia está contemplada nos objetivos, destacando a importância de oportunizar a interação da sociedade com a informática. E também aponta a importância de oportunizar um espaço onde o educando e a comunidade possam estar em contato com as tecnologias e principalmente construindo aprendizagens, educando para uma cidadania global numa sociedade tecnologicamente desenvolvida.

Considerando o PPP da escola $Y$, não foram encontrados projetos préestabelecidos sobre informática. O assunto tecnologia é tratado como "materiais e 
equipamentos para auxiliar professores e alunos no desenvolvimento de atividades pedagógicas dentro e fora da sala de aula".

A escola possuí uma sala onde funciona o laboratório de informática [...]. Contamos também com recursos tecnológicos, sendo 11 computadores, 3 impressoras, 1 rádio Microsystems, 1 caixa de som amplificada, 1 aparelho de DVD, 1 câmera digital, 1 televisão 29", uma televisão 21" e uma antena parabólica (PPP, escola Y).

Podemos inferir que na escola $Y$ assim como em outras escolas analisadas a tecnologia é vista apenas como um "recurso material" e não como inserida nas atividades pedagógicas aliada aos processos de ensino e aprendizagem dos alunos.

\section{Categoria 3 _ Planejamento e desenvolvimento de projetos pelos professores usando as TDIC.}

Nesta categoria analisamos se os professores planejam e desenvolvem projetos com os alunos usando as TDIC. Percebemos, pelas respostas ao questionário, que alguns professores realizam projetos com seus alunos em parceria com outros professores e/ou o professor do laboratório de informática.

P2. Sim, inclusive no encerramento do projeto água foi feito um cultural game com vídeos, jogos e fotos.

P18.Tínhamos um projeto com parceria do governo federal chamado UCAUm Computador por Aluno onde, os alunos utilizavam 3 vezes por semana.

Outros professores, todavia, alegam que não realizam projetos.

P1. Não, porque nossos alunos ainda não possuem tanto conhecimento.

P22. Não, apenas são agendadas aulas em horário fixo para os professores do ensino fundamental.

P33. Não, apenas como complementação da aula teórica. 
Podemos observar pelas respostas dos professores que muitas vezes as TDIC são utilizadas apenas como um recurso multimídia para apresentação de slides ou ilustração de uma "aula teórica".

Muitas vezes observamos que 0 professor tem pouco ou nenhum conhecimento sobre tecnologia e fica com receio de demonstrar para os alunos e por isso acaba não utilizando. Isto nos remete a uma concepção tradicional de educação, onde o professor é o dono do saber e não admite aprender com seus alunos.

\section{Categoria 4: A contribuição das tecnologias digitais da informação e comunicação nos processos de ensino e de aprendizagem}

Nesta categoria analisamos as concepções dos professores sobre a contribuição das TDIC nos processos de ensino e de aprendizagem

Analisando as respostas do questionário, $100 \%$ dos participantes disse que sim, que as tecnologias podem auxiliar. Porém alguns ressaltaram que auxilia se for trabalhada de forma dinâmica e organizada,

P2. Ela, hoje em dia, é fundamental na construção da aprendizagem, principalmente se a criança possuir alguma dificuldade cognitiva ou motora.

P23. Sim, de várias formas; pesquisas, leituras, jogos, atividades em geral que vem ao encontro ao que é trabalhado em sala de aula.

P24. Por que ao utilizar os tais programas e sites eles estarão aprendendo, desenvolvendo a criatividade e o processo de leitura e escrita.

Nessa perspectiva como refere Kenski (2003) não resta apenas ao sujeito adquirir conhecimentos de informática para poder desfrutar das possibilidades interativas com as tecnologias. O impacto das tecnologias "[...] reflete-se de maneira ampliada sobre a própria natureza do que é ciência, do que é conhecimento" (KENSKI, 2003, p. 75). Demanda uma reflexão intensa sobre as compreensões do que é o saber e sobre as formas de ensinar e aprender e de como o sujeito constrói conhecimento. 


\section{Categoria 5. A utilização das TDIC no processo de avaliação}

Nesta categoria analisamos se os professores estão utilizando as TDIC no processo avaliativo dos alunos.

A maioria dos participantes coloca que a tecnologia auxilia no processo de avaliar e citam ainda que podem ver outras habilidades que não conseguiriam ver na sala de aula.

P1. Sim, pois em muitos processos de desenvolvimento que a criança possa não demostrar dentro da sala de aula, pode demonstrar com habilidades durante a utilização da TDIC. E podemos o avaliar num todo como ser crítico e pensante.

P10. Sim, pois utilizando as tecnologias você pode observar 0 desenvolvimento do aluno, da sua criatividade, interesse, podendo verificar o que ele ainda precisa aprender.

\section{DISCUSSÃO E RESULTADOS}

Enquanto equipe de investigação, defendemos a necessidade de, durante a sua formação inicial ou através da sua formação continuada ou em serviço, aos professores sejam oferecidos programas atualizados e inovadores relacionados às tecnologias digitais de informação e comunicação. As análises evidenciam, inicialmente, uma intenção dos professores em conhecer e se apropriar da tecnologia, entendendo seus limites e potencialidades. Nem tudo o que se pensa fazer é viável, seja pelas condições dos equipamentos, do conhecimento técnico, seja mesmo pelo acesso aos laboratórios por parte dos alunos. Percebemos também que, mesmo a utilização das tecnologias digitais estando contemplada no projeto político pedagógico da escola, muitos professores não a utilizam. Aliás, muitos dos professores entrevistados desconhecem o conteúdo do PPP da escola e alegam que está em construção ou pouco acessível aos professores. Alguns assinalam que existem dificuldades de acesso à internet e por vezes os próprios professores pagam para os alunos poderem utilizar. Muitos citam a inexistência de laboratórios para a utilização com os alunos. Sabem da importância, porém não existe infraestrutura necessária na 
escola. Os computadores, muitas vezes antigos, não suportam os programas e travam dificultando o desenvolvimento das atividades. Outra questão que dificulta a utilização das TDIC é a formação dos professores, que relatam ser o resultado de uma prática pedagógica na qual não existiam muitas tecnologias e quando utilizadas em sala de aula eram com o objetivo de recreação e não necessariamente como instrumento dos processos de ensino e de aprendizagem. Alguns dos professores acreditam que as tecnologias auxiliam na avaliação, pois os alunos podem ser avaliados, não apenas de forma tradicional como geralmente é feito, mas de variadas formas, levando em consideração que cada aluno tem uma maneira particular de aprender e consequentemente de expor o que aprendeu. Na sala informatizada é possível observar o que o aluno é capaz de desenvolver, criar, solucionar, utilizando as ferramentas que estão à sua disposição. Muitos dos professores entrevistados não se sentem seguros para utilizar as TDIC com seus alunos, alegando que eles são nativos digitais e apresentam maior fluência tecnológica. Percebemos, pelos dados, a necessidade da formação continuada para os professores da educação básica de modo que eles possam incorporar a tecnologia nas suas práticas pedagógicas.

\section{CONSIDERAÇÕES FINAIS}

Conclui-se que os professores vivenciam desafios constantes para integrar a tecnologia no currículo com propostas que privilegiem a autoria, a cooperação e o trabalho em rede. Fala-se insistentemente em inclusão. E a inclusão digital? Muitas escolas não estão excluindo seus estudantes da cultura digital e desta forma das oportunidades de trabalho e acesso à sociedade do conhecimento? Estas questões precisam ser amplamente discutidas para que todos os estudantes tenham seus direitos assegurados e não fiquem apenas registrados nos documentos. Percebemos também pelos nossos estudos que muitos professores fazem um excelente trabalho utilizando as TDIC, porém não divulgam para a comunidade, por isso a importância da construção de blogs e sites nas escolas. 


\section{REFERÊNCIAS}

ALMEIDA, Maria Elizabeth B.; VALENTE, José A. Tecnologias e Currículo: trajetórias convergentes ou divergentes? São Paulo: Paulus, 2011.

ARAGÓN, Rosane. Ambientes Virtuais de Aprendizagem: do "ensino na rede" a "aprendizagem em rede". Salto para o futuro, 2005. Disponível em: <http://www.tvebrasil.com.br/salto/boletins2005/nfa/tetxt2.htm>. Acesso em: 10 ago. 2015.

BELLONI, Maria L. Educação a Distância. Campinas: Autores Associados, 2001.

O que é Mídia-Educação. Campinas: Autores Associados, 1995

BRASIL, Ministério da Educação. Secretaria de Educação Básica. Diretoria de Currículos e Educação Integral - DICEl. Coordenação Geral do Ensino Fundamental COEF. Elementos conceituais e metodológicos para definição dos direitos de aprendizagem e desenvolvimento do ciclo básico de alfabetização (10, $2^{\circ}$ e $3^{\circ}$ anos) do ensino fundamental. Brasília, DF: MEC, 2012.

KENSKI, Vani Moreira. Tecnologias e ensino presencial e a distância. Campinas, SP: Papirus, 2003.

SILVA, Ezequiel Theodoro da. A leitura nos oceanos da Internet. São Paulo: Cortez, 2003.

Revalorização do livro diante das novas mídias. Veículos e linguagens do mundo contemporâneo: a educação do leitor para as encruzilhadas da mídia. Disponível em: <http://portal.mec.gov.br/seed/arquivos/pdf/1sf.pdf>. 2005. Acesso em: 10 abril 2015.

ZIEDE, Mariangela Kraemer Lenz; ARAGON, Rosane. Docência no Ensino Superior: inovando e reconstruindo práticas pedagógicas na educação a distância. Currículo sem Fronteiras, v. 14, no 3, p. 254-279, 2014. 